\title{
国 \\ Stock Market Manipulation on the Hong Kong Stock Exchange
}

\author{
Dionigi Gerace', Charles Chew², Christopher Whittaker ${ }^{3}$ and Paul Mazzola4
}

\begin{abstract}
This study is the first to empirically examine stock market manipulation on the Hong Kong Stock Exchange. The dataset contains 40 cases of market manipulation from 1996 to 2009 that were successfully prosecuted by the Hong Kong Securities \& Futures Commission. Manipulation is found to negatively impact market efficiency measures such as the bid-ask spread and volatility. Markets appear incapable of efficiently responding to the presence of manipulators and are characterised by information asymmetry. Manipulators were successfully able to raise prices and exit the market. This finding contradicts views that trade-based manipulation is entirely unprofitable and self-deterring. The victimisation of information-seeking investors and the market as a whole provides a strong rationale for all jurisdictions, including Australia, to have effective laws that prohibit manipulation and for robust enforcement of those laws to further deter market manipulation.
\end{abstract}

Keywords: market manipulation, market misconduct, Hong Kong Stock Exchange, market microstructure, securities regulation.

JEL Code: G18, G28, K22

\footnotetext{
${ }^{1}$ Faculty of Business, University of Wollongong.

${ }^{2}$ Faculty of Law, University of Wollongong.

${ }^{3}$ School of Accounting and Finance, Faculty of Commerce and the Faculty of Law, University of Wollongong. This paper is an abridged and updated version of my thesis for the Degree of Bachelor of Laws Joint Honours by Research. I have greatly benefited from the wisdom and guidance of my Honours Supervisors, Dr Dionigi Gerace and Dr Charles Chew. The views expressed in this article are my own. They do not reflect the views of my employer, the Australian Securities and Investments Commission. I am grateful for the experienced advice of my colleagues. Any errors/omissions are my own.

${ }^{4}$ Faculty of Business, University of Wollongong
} 


\section{What is Market Manipulation?}

Market manipulation is among the oldest and most harmful practices in global share markets. It victimises individual investors, erodes public confidence in market integrity and undermines market efficiency. By creating artificial, false or misleading stock prices, manipulators harm legitimate traders who are forced to transact at distorted levels that do not efficiently reflect corporate value. Manipulation harms market efficiency by disrupting with the process by which prices reflect the market forces of supply and demand.

Market manipulation has long been recognised as harmful although there is little empirical evidence supporting this concern. By demonstrating the negative impact of actual cases of market manipulation on the Hong Kong Stock Exchange (HKSE), this study assists in building a rationale for why securities regulators must continue to actively strive to prohibit market manipulation.

Defining manipulation is no simple task. The Oxford English Dictionary defines 'manipulate' as 'to manage by dexterous contrivance or influence; especially to treat unfairly or insidiously for one's own advantage.' Market manipulation is not defined in the Corporations Act 2001 (Cth) or the CAP 571 Securities and Futures Ordinance (Hong Kong). Laws prohibiting manipulation generally describe manipulation as involving the creation of 'artificial' or 'false' market prices yet the meaning of such prices is a matter of sharp controversy (Goldwasser 1999, p.100). The absence of a statutory definition has led to a lack of agreement amongst courts and commentators as to what precisely constitutes manipulation. The effectiveness of the law must be called into question if manipulation cannot be defined with precision.

Attempts to define manipulation must adequately distinguish manipulation from legitimate trading. Jarrow (1992 p.311) defined a manipulative trading strategy as one 'that generates positive real wealth with no risk'. This definition is unsatisfactory as it could easily define many legitimate arbitrage activities. Arbitrage is similarly defined as a 'zero-risk, zero-net investment strategy that still generates profits.' (Bodie, Ariff, Rosa, Kane \& Marcus 2007). According to the efficient market hypothesis that Fama (1970) famously asserted, arbitrage trading may be seen as economically desirable given that it improves the efficiency of the pricing of assets that are traded on multiple markets.

Some clarity may be gained by defining manipulation as fraud. 'False' trading falls easily within the conceptual confines of fraud as such trading involves deceptive trading designed to fool ordinary investors. One example of a 'false' trade is a wash trade in which the manipulator buys and sells the same security in a trade that involves no change in beneficial ownership. Wash trades intentionally mislead ordinary investors into a mistaken belief that the stock is more actively traded than it 
really is. Wash trades involve both fraudulent conduct (false trade itself) and a fraudulent purpose (to give a false impression to the market).

The usefulness of defining manipulation as fraud breaks down when examining other types of market manipulation. Manipulation may encompass a transaction that has both a willing buyer and seller but is transacted solely for an illegitimate purpose. For example, as in the case of ASIC v Soust [2010] FCA 68, an executive bought shares at excessively high prices from willing counterparties in order to push the price of shares up to qualify for a performance bonus. While these trades were not conducted in good faith, they involved no fraudulent conduct as the trading was not, by itself, fraudulent. The reason why the conduct is considered manipulative is that the illegitimate purpose colours the otherwise legitimate trading as manipulative. In his classic judgement on market manipulation, Mason $\mathrm{J}$ noted in North $v$ Marra Developments (1981) 148 CLR 42, 59 that in the 'absence of revelation of their true character (these transactions) are seen as transactions reflecting genuine supply and demand'. Professor Loss, invariably described as the Father of modern securities law, has noted that manipulation is 'related to the field of fraud but not altogether a part of it as a matter of legal analysis' (Loss \& Selgman 2004).

The definitional and enforcement challenges of market manipulation led Fischel and Ross (1991) to claim that the legal concept of 'market manipulation' should be abandoned altogether. They claimed that non-fraud based manipulation, where the manipulator attempts to move prices to artificial levels solely by trading will not be successful due to symmetrical price pressure effects (1991, p.519). They conclude that the law need not prohibit such sure-to-lose manipulation that must always be unprofitable and entirely self-deterring (1991, p.553).

Even if trade-based manipulation is unprofitable, this does not support Fischel and Ross's claim that manipulation involves no harmful outcome. By distorting the price-formation process, even if there is a genuine and willing counterparty, manipulation gives a false price signal to ordinary investors who believe the price reflects genuine supply and demand. If it is argued that only all market forces (whether in good faith or not) can give a correct price, it is worth recalling that the laws of conspiracy, attempts and other crimes demonstrate the criminal law is concerned with more than just harmful acts.

Recently the High Court of Australia, for the first time, considered the modern Corporations Act 2001 (Cth) anti-manipulation provision in Director of Public Prosecutions (Cth) v JM (2013) 298 ALR 615. The full court declined to narrow the application of the law to particular manipulative techniques and merely restated the prevailing understanding that artificial prices are prices that exist contrary to the forces of 'genuine' supply and demand. The key determinant of 'genuine' supply and demand is that buyers seek to acquire at the lowest available price and sellers seek to 
sell at the highest realisable price [at 71]. This alone would be insufficient to adequately distinguish manipulator from genuine trader. But the court went on to note that a manipulator must have the dominant purpose of establishing such an artificial price [at 75]. This acknowledgement validates many commentators' view (such as Loke 2007 and Huang 2009) that the vital defining characteristic of a manipulator is having an illegitimate purpose or intent. Accordingly this paper adopts this understanding of market manipulation as involving an interference with the forces of genuine supply and demand for an illegitimate purpose. What this definition fails to do is provide industry with certainty as to what precisely manipulation entails. In our fast-paced and evolving financial markets who defines what practices as illegitimate?

Further guidance may be obtained by the from the United States ('U.S.') position. The U.S. is the pre-eminent securities law jurisdiction possessing the largest stock exchange in the world, a sophisticated jurisprudence on market manipulation and an acknowledged reputation for dealing effectively with abusive market practices. Australia and Hong Kong have adopted in a piecemeal fashion many of the laws of the Securities Exchange Act 1934 (U.S.) relating to market manipulation. This legislation was enacted by the Roosevelt administration following the 1929 NYSE market crash and resulting worldwide Great Depression. The enactment of these laws was designed to protect the public interest beyond the suppression of mere fraud.

The US Supreme Court has stated, in Santa Fe Industries Inc v Green that the word 'manipulative' is virtually a 'term of art' reflecting Congress's intention 'to prohibit the full range of ingenious devices that might be used to manipulate securities' (430 U.S. 462, 477 [1977]). In giving rule-making authority to the SEC to define practices as manipulation it appears that Congress regarded 'manipulation as a flexible concept which would encompass schemes that might hatch in the future from the fertile and creative brains of dishonest market operators' (Poser 1986 p.672). The merits of flexibility notwithstanding, there must be a core definition of manipulation.

While manipulation is difficult to define, some manipulative practices are readily identifiable. Manipulative trading techniques are known by a whole manner of colourful descriptions such as 'wash trading', 'pump and dump' and 'churning and burning' to name a few. Manipulation need not necessarily involve any trading at all. The practice of rumourtage involves spreading false or misleading rumours about company value in order create artificial or false stock prices. Amid the carnage of the Global Financial Crisis (GFC) for example, the Australian Securities and Investments Commission (ASIC) became concerned that negative and untrue rumours were being fabricated and spread by entities that had large short positions in the market. By pushing prices further down than they ought to go, the corporate regulator was concerned that manipulators may have attempted to capture illegitimate profits. 
While this paper exclusively examines share market manipulation, manipulation of other markets obviously also occurs. The historic manipulations of the commodities like soybeans and silver have slipped into industry folklore for their audacity. More recently financial markets have been shocked at the revelations and extent of the manipulation of the benchmark interest rate, the London Interbank Offer Rate (LIBOR), a rate which underpins $\$ 350$ trillion in globally traded derivatives. To date, three large investment banks have been fined hundreds of millions of dollars for their part in the manipulation of LIBOR and criminal proceedings against individual traders have commenced.

It is the ready transferability of securities on exchanges that makes such markets highly susceptible to manipulative techniques. As global equity markets increase in complexity, there is no doubt that the number of techniques of manipulating those markets will also increase. In Australia, the way securities are traded has evolved from manual processes to the use of predominately automated systems by stockbrokers. Further technological innovations have led to the rise of High Frequency Trading (HFT) which usually involves very fast trading by computers executing strategies derived from complex algorithms. Market structure changes have also fundamentally altered the way people trade securities. The introduction of competition to the Australian Stock Exchange (ASX) by the licensing of a new rival exchange, Chi-X, has enabled meaningful multi-market trading in Australia for the first time. Finally equity market liquidity is fragmenting with large amounts of trading now occurring off 'lit' exchanges in the crossing systems of large investment banks, known as 'dark pools'.

Markets Regulators around the world are struggling to adapt legal frameworks to the new world of complex trading. Recently the Investment Industry Regulatory Organisation of Canada (IIROC) (2012) released proposed guidance on prohibiting particular forms of manipulation namely 'layering', 'quote manipulation', 'spoofing' and 'abusive liquidity detection' that arguably are enhanced in a computerised highspeed and multi-market trading environment. The U.S. Court of Appeals rightly noted in Cargill Inc $v$ Hardin that the 'techniques of manipulation are limited only by the ingenuity of man' (452 F.2.d 1154, 1163).

There is a danger that law-makers and regulators will confuse market manipulation with the latest changes in market technology and structure. The ASX has noted that it is 'often problematic to distinguish between what is manipulative and trading activity that is evidence of the competition for the smartest, fastest and most profitable algorithm' (2011, p.39). Nevertheless, it is vital that law-makers ensure law reform is sophisticated enough to only target actual manipulation without impeding the natural evolution of the market. Fast computerised trading, in itself, is not market manipulation. In fact, HFT appears to provide vital liquidity to equity markets and has 
been shown to be negatively correlated to end-of-day price dislocations, a proxy for manipulation (Frino \& Lepone, 2012). This suggests that more automated exchanges may actually be less susceptible to market manipulation. More automated exchanges may face other challenges however such as the technical glitch which lead to the 6 May 2010 flash crash where the Dow Jones Industrial Average plunged down 9\% only to recover those losses within minutes. After conducting detailed studies into HFT and Dark Pools (2013) and consulting with industry, ASIC has adopted a cautious and nuanced approach that attempts to target manipulation without unduly impeding the ability of Australian equity markets to develop in sophistication. The ASX Chief Executive, Elmer Funke Kupper has backed ASIC's approach stating that the regulator's decisions on market structure 'have left us in a better position than many other western markets' (Liondis 2013).

The consensus view is that carefully targeted laws are required to effectively prosecute and deter harmful market manipulation. By distorting a market's price formation and discovery process and victimising legitimate investors, market manipulation is generally understood as having a severely negative impact on market efficiency and integrity. The potential harm of manipulation is particularly concerning in an Australian context given the enormous potential for 'Mum and Dad' investors, invested to the sum of $\$ 1.58$ trillion in markets via superannuation, to be ripped-off. Markets with higher incidences of manipulation would appear more likely to have higher costs of capital, a vital measure that companies use in evaluating whether to engage in their business (Modigliani and Miller 1958). In this way, manipulation undermines the very purpose of financial markets, being the cost-effective transfer of investment from those in financial surplus to those in financial deficit.

Despite this consensus view there is a severe absence of empirical research that demonstrates how market manipulation actually harms markets. According to Goldwasser (1999), this has led to the unsatisfactory position of not knowing how often real-world prices are manipulated, how much harm manipulation does or how manipulation laws influence behaviours (1999, p.188). She asserts that laws prohibiting manipulation are said to operate in a 'conceptual vacuum' with little discussion of the underlying policy consideration or analysis of the effectiveness of the overall scheme of regulation (1999, p.149).

This study's empirical study of actual cases of market manipulation on the Hong Kong Stock Exchange attempts to fill a portion of this conceptual vacuum. Doing so, it refutes Fischel and Ross's (1991) view that trade-based manipulation is unprofitable and self-deterring. The demonstrated harm of manipulation to market efficiency and integrity provides policy-makers in all jurisdictions an evidence-based rationale and some justification for evaluating legal responses designed to prosecute and deter this harmful crime. 


\section{Literature Review}

\subsection{Introduction and Information Asymmetry}

Despite the absence of empirical work, there is a flourishing of theoretical work that examines market manipulation drawing on market microstructure theory. Ever since the insightful commentary of Bagehot (1971) market microstructure analysis has developed into a useful tool to understand market exchange, particularly when some parties know more than others.

Since the seminal work of Fama (1970), share markets have constantly been held up to the standard of a perfectly competitive and efficient market in which pricetaking investors buy and sell shares so that prices fully reflect all available information about a company's prospects. Ideally the price at which exchange takes place is efficient, reflecting all public and private information about a company's prospects. In reality, stock markets fall short of this ideal. The separation of ownership and management necessitates a minimum information asymmetry in stock markets. Privileged parties may possess better or non-public information and the rest of the market knows it. Manipulators may be capable of fooling rational informationseeking investors into trading at artificial prices by capitalising on market perceptions that some people know more than others.

\subsection{Market Microstructure Theory}

The key measure in market microstructure theory is the bid-ask spread. The spread is the difference in price and quantity preferences of buyers and sellers. When traders' preferences overlap, a trade occurs. One significant component of the spread is an adverse selection risk associated with market information asymmetry (See Copeland \& Galai 1983; Glosten \& Milgrom 1985; and Kyle 1985). Where a market participant trades with an 'informed' trader who possesses special information that they do not possess, they always make a loss (Bagehot 1971, p.14)

Benston and Hagerman (1974) hypothesised that this component related to a share's unsystematic risk, being the risk that results from the market adjustment to the company firm specific information like earnings announcements, executive appointments etc. Markowitz (1959) originally found that this unsystematic risk could be eliminated as the number of securities approached infinity.

Where a market participant suspects the existence of informed traders they increase the spread (cost) of transactions to discourage such trading and compensate themselves by making more money out of price-taking liquidity traders. By increasing the cost of trading, information asymmetry decreases a market's liquidity (Kyle 1985, p.1317). 
Krinsky and Lee (1996) demonstrated the impact of information asymmetry by finding that spreads widen before the public release of information and narrow afterwards. While increasing the spread is a rational response to the prospect of informed trading, higher spreads negatively impacts the efficiency of the market.

Spreads have also been observed to widen for large trades. Trades themselves may convey 'informed' information. Easely and O'Hara (1987) explain that trade size contains an informational risk as only 'informed' traders seek to trade in as large amounts as possible to take full advantage of their information before it becomes public (1987, p.70). This fact may explain why large transactions tend to be traded at worse prices (Kraus \& Stroll, 1972). Thus both the bid-ask spread and the size of transactions may be used as a proxy for the level of market information asymmetry.

\subsection{Strategic Manipulative Trading}

Many foundational models postulate that successful market manipulation involves the manipulator giving out false signals to fool information-seeking investors into thinking he or she is a truthful 'informed' trader (Kyle 1985; Allen \& Gale 1992; Kumar \& Seppi 1992; Fishman \& Hagerty 1992). Active information-seeking investors normally keep markets efficient by identifying 'informed' traders and trading alongside them, reducing the profits of non-public information and increasing the information in stock prices (Thel 1994, p.231). By conveying false 'private' information (false positives), manipulations are able to capture profits by trading against these information-seeking investors (Kim \& Jungsoo 2010, p.298).

Some trading practices may be so indicative of an informed trader that the manipulator will be able to achieve the desired result by mimicking them. For example, a manipulator might increase a security's price by aggressively purchasing before an earnings announcement to suggest that people with valuable non-public information are buying (Thel 1994, p.241). Duped information-seekers will copy, pushing up the price of the stock. The manipulator sells at the high level before the public announcement and the inevitable price adjustment back down to equilibrium prices.

Allen and Gale (1992) have modelled the possibility of successful manipulation where the manipulator pools (or trades alongside with) an informed trader. The informed trader anticipates, perhaps because of inside information, that favourable information about the stock will be revealed in the future. Consequently the informed trader begins buying the undervalued stock. Information asymmetry is introduced into the model, as information-seekers are unable to tell if the trader is actually informed or not. By simply imitating the trading of the informed trader, the manipulation can profit simply by buying and selling the stock. It is this pooling that 'allows manipulation to be profitable' (1992, p.517). 'As investors are uncertain if the 
informed trader is actually informed, they are prepared to trade with him for lower than the informed trader's expected value. As time passes, the information is priced into the stock as it rises and the informed trader exists his position' (1992, p.509).

Allen and Gale rely on the assumption that there is an informed trader for the manipulator to imitate in order for manipulation to be profitable. The model relies on information asymmetry. To be successful, manipulators must convince the market they are informed traders, not manipulators, as no trader would trade with a manipulator where they are guaranteed to lose money (Thel 1994, p.245). For a manipulator to know the identity of informed traders or to credibly pose as an informed trader, a manipulator's own identity is important.

Many studies have suggested that certain parties have an incentive to manipulate given their market-wide status as likely informed parties. Scholes first noted that corporate insiders have monopolistic access to information about their firms (Scholes 1969). When paid in stock options, corporate insiders have a clear incentive to strategically influence the value of their derivative position (Vanden 2005). Further, Niederhoffer and Osbourne (1966) originally pointed out that exchange specialists, brokers and market makers also have monopolistic information and may be seen as reliable and informed parties. Hillion and Suominen (2004) identify an agency-based model of closing price manipulation suggesting these brokers themselves may manipulate the closing price of a stock in order to give a better impression of their executions to their customers. More obviously, a 'large investment bank, prior to executing a merger or acquisition transaction may manipulate prices of the stock of the company in question' (Hillion \& Suominen 2004, p.370). An investment bank may manipulate to ensure their corporate advice is a self-fulfilling prophecy.

The microstructure theory that informed parties have an incentive to manipulate has empirical support. In the first empirical examination of market manipulation, Aggarwal and $\mathrm{Wu}$ (2006) used an event study to examine 142 prosecuted cases of stock market manipulation on U.S. stock markets. They found that manipulators were mostly 'informed' parties such as corporate insiders, underwriters, large shareholders and market makers who successfully manipulated prices to higher 'artificial' levels (2006, p.1948). In Aggarwal and Wu's empirical study of manipulation $47 \%$ of cases involved corporate insiders such as executives and directors; 64\% involved stockbrokers; 9\% involved market makers and 32\% involved large shareholders with at least $5 \%$ of company equity ownership (2006, p.1937).

Aggarwal and $\mathrm{Wu}$ found most of the manipulation in dataset occurred in relatively inefficient markets. These markets are characterised by small size and low liquidity, often not having appropriate regulatory oversight or disclosure 
requirements. They found that manipulators normally targeted shares with very low average trading volumes and market capitalisation, so called 'penny stocks' (2006, p.1936). By comparison, the largest stock exchange in the world - the New York Stock Exchange (NYSE) was relatively free of manipulation constituting only $2.11 \%$ of their sample manipulation (2006, p.1936). This empirical supports the view that manipulation is more likely for stocks with low liquidity/volumes as these markets have an inelastic supply curve. The purchases of a manipulator then may have a larger price impact than would otherwise occur in a more liquid market. Thus manipulation of prices is easier with thinly-traded stocks (Thel 1994, p.231).

Importantly, Aggarwal and $\mathrm{Wu}$ found that manipulators were successfully able to create artificial prices and sell at these high levels before prices returned to their true value (2006, p.1948). The victims of manipulators were information seeking investors (such as arbitrageurs), potentially fooled by false positives. In the presence of manipulation, increasing the number of information-seeking investors does not enhance market efficiency but merely increases the profits of manipulators. In these situations 'the need for government regulation is acute.' (2006, p.1916). Aggarwal and $\mathrm{Wu}$ conclude that their results suggest 'a strong role for government regulation to discourage manipulation while encouraging greater competition for information' (2006, p.1947). Aggarwal and Wu (2006) event study model is used in Part 3's empirical study of manipulation on the Hong Kong Stock Exchange.

\subsection{Categorisation of Manipulative Techniques}

Market manipulation techniques can range from crude devices to highly sophisticated schemes. The literature broadly defines manipulative techniques into 3 categories, namely trade-based, action-based and information-based manipulation (Allen \& Gale 1992 , p.505). While these distinctions often overlap, they are nonetheless useful to demonstrate the variety of methods of manipulation.

\subsubsection{Trade-Based Manipulation}

Trade-based manipulation is due solely to buying or selling of securities without the manipulator taking actions to alter the value of the firm or using false information. Jarrow (1992) suggested that large uninformed traders with market power could manipulate prices to their advantage and generate profits at no risk (1992, p.332). Profitable manipulators aimed to create 'price momentum' so that an increase in price caused by the manipulator's trade at one date tended to increase prices at future dates. Jarrow also showed that profitable manipulation is possible where the manipulator corners the market (1992, p.313). Contrastingly, Allen and Gale (1992) found that manipulation is possible even when there is no price momentum and no possibility of a corner by the aforementioned pooling with an informed party (1992, p.506). 
By challenging typical market microstructure assumptions, Allen and Gorton (1992) demonstrated that profitable trade-based manipulation is possible in markets that display information asymmetry. The common microstructure assumption is that 'liquidity' traders have exogenous preference to trade immediately and must therefore pay the spread. Allen and Gorton note that this assumption does not accord with reality. While traders have all sorts of needs for cash immediately, it is difficult to understand why a trader is so desperate to buy shares that they disregard the price. Clearly liquidity sales are more likely than liquidity purchases (1992, p.625). As liquidity sales are more likely than purchases, there is less information in a sale than a purchase because the trader is less likely to be informed (1992, p.625). This natural asymmetry leads to asymmetrical price responses as the bid price will move less in response to a sale than does the ask price in response to a purchase. Allen and Gorton suggest that a manipulator can engage in profitable manipulation by repeatedly buying stock, causing a relatively large effect on prices and then sell with relatively small effect (1992, 625). Allen \& Gorton (1992) appear to refute Fischel and Ross's suggestion that trade-based manipulation cannot profit because price effects as symmetrical (1991, p.519).

Kumar and Seppi (1992) also demonstrated the possibility of profitable tradebased manipulation by a manipulator pooling with an informed trader. In their model, a manipulator buys a number of stock market index futures. The manipulator then trades alongside an informed trader, bidding up the shares underlying the index thereby raising the settlement price he obtains on expiry of the futures contract. If the futures position is larger than the spot position, the net expected gain is positive (1992, p.1486). This manipulative technique is colloquially known as 'punching the settlement price'.

The feasibility of Kumar and Seppi's model of cross-market manipulation applying is limited but certainly not impossible. The manipulator would incur substantial transaction costs by trading the whole basket of shares underlying the index (1992, p.1497). Risk aversion in taking so large a position may stop the manipulator. The manipulator would also need an exceptionally large position in the market to move the index otherwise his return at delivery of the futures would be inadequate to cover his spot market trading. Risk aversion in taking so large a position may stop the manipulation. Despite these limitations, the most audacious case of market manipulation in Australia to date involved exactly the type of manipulation Kumar \& Seppi (1992) described.

That case was Australian Securities Commission v Nomura (1998) 160 ALR 246. Nomura had a large arbitrage position in index futures on the Sydney Futures Exchange, known as SPI contracts in securities traded on the ASX. Nomura held 10,912 contracts due to expire on the $29^{\text {th }}$ of March 1996. It held a 'matching' basket 
of shares reflecting the index, as part of its arbitrage position worth \$AUD600,000,000. The expiry price of the SPI contracts was determined by the closing price of the level of the All Ordinaries on that day. Nomura attempted to manipulate the expiry price of the futures to captures profits from its arbitrage position. First it gave instructions to brokers to aggressively sell near the close of trading on the $29^{\text {th }}$ without concern for price. Secondly, Nomura instructed brokers to buy the same shares just sold at prices substantially below the last traded price. For most illiquid securities, the bid price was 5\%-20\% less than the last recorded sale. Had all brokers carried out their instructions correctly, Nomura would have moved the closing price of the All Ords down and made significant speculative profits in its SPI contracts. In the case of two illiquid stocks, the brokers 'hit' the bid basket and Nomura effectively bought its own shares at depressed prices. The court did not accept Nomura's argument that it was legitimately unwinding an arbitrage position (at 249). His Honour Sackville J found that in seeking profits, Nomura intended to create a false and misleading appearance of active trading on the ASX (at 250). Just because it had an economically legitimate goal (arbitrage) 'did not necessary mean that all strategies associated with that objective were lawful' (at 345).

\subsubsection{Action-Based Manipulation}

Unlike trade-based manipulation, action-based manipulation involves a manipulator influencing the beliefs of other traders to change the perceived value of the firm. Strategic trading by manipulators to capitalise on market perceptions of them as 'informed' fall within this type of manipulation (Vila 1989).

Several studies have claimed that action-based manipulation is possible when the informed manipulator first trades in the wrong direction of their information (Kose \& Narayanan 1997) (Huddart, Hughes \& Levine 2001) (Chakraborty \& Yilmaz 2004). This 'noise' trading is done to confuse investors into believing the informed trader is not trading on his private information. This results in reduced informativeness of his or her subsequent disclosures because the "market is no longer sure whether an insider buys (sells) indicates good (bad) news' (Kose \& Narayanan 1997, p.217). This noise trading acts as camouflage for their real manipulative transactions in the right direction of their information. For example, an insider who knows that the prospects of a certain company are not good might actually start buying in order to drive its price up and then sell without its price falling too fast. In the Chakraborty and Yilmaz's model, this 'noise' allows the informed manipulator to profit in every equilibrium (2004, p.133).

Gerald and Nanda (1993) demonstrated the possibility of action-based manipulation around seasoned equity offerings. An 'informed' manipulator, possessing private information about an upcoming stock issue, can influence the issue 
price by short selling shares before the issue. Seizing on the informativeness of his trades, information-seeking investors will copy him, pushing overall market prices down. The manipulator's selling actually conceals his knowledge about the upcoming float and sends a false signal to the market. Manipulative trading decreases the informativeness of the secondary market order flow, thereby exacerbating the winner's curse problem faced by uninformed bidders and leading to an increase in the seasoned offering discount required to float the offering (1993, p.214).

To ensure the success of the float, the issuing company is forced to issue the new shares at a discount from (manipulated) secondary market prices. In subscribing to the new issue, the manipulator recoups his losses by purchasing shares at significant discounts in the offering. Gerald and Nanda have found that the magnitude of the discount required to successfully float the offering is directly related to the expected occurrence of manipulation. Manipulation will occur when the informed investor expects to secure significantly more shares in the offering than the number of shares he needs to trade in the pre-issue secondary market to conceal his information (1993, p.217).

The ability of a manipulator to profit from strategic trading depends on the price response asymmetries in the market. Manipulators need to be able to earn more from trading in the right direction than from trading in the wrong direction. Benabou and Laroque (1992) have shown that various informed parties (corporate officers, financial journalists and investment 'gurus') have the incentives to manipulate stock markets through strategically distorted pubic announcements or forecasts (1992, p.921). Their model begins with an insider who knows that that returns on a stock will rise. Instead of merely engaging in insider trading, this informed party could earn more by forecasting low returns to the public and then buying up the stock at depressed prices (1992, p.923).

Benabou and Laroque use game theory to develop a model where informationseeking investors can constantly reassess this investment guru's credibility over time. Rational speculators may even attach credibility to a dishonest informed party because she or he may still reveal some genuine information out of concern for her or his reputation. The ability of these insiders to manipulate over the long run is limited only by the public's constant reassessment of their credibility (1992, p.922). Where the manipulator gives out false information, observation over many announcements will help the market learn whether the insider is an untruthful manipulator and her or his creditability will accordingly plummet (1992, p.922).

Bagnoli and Lipman (1996) considered the possibility of profitable actionbased manipulation in the context of takeover bids. In periods of high takeover activity, a manipulator may announce a fake takeover bid for a company. Since the information-seekers cannot tell if the bid is serious, they will rationally start 
purchasing and drive market prices higher. At this point, the manipulator drops his takeover bid, which had been fake from the beginning, and sells at the higher market price (1996, p.126) For example in what was considered widely questionable behaviour, an aborted takeover bid for David Jones Ltd in June 2012 caused shares in David Jones to jump 15\% higher before dropping more than 10\% (Metherell 2012).

\subsubsection{Information-based Manipulation}

Information-Based Manipulation is manipulation based on releasing false or misleading information or rumours (Allen and Gale 1992, p.505).

Van Bommel (2003) investigated the manipulative strategy known as 'rumourtage' - the spreading of false rumours to move prices to an artificial level and obtain trading profit (2003, p.1499). In the Van Bommel model, the informed manipulator spreads a binary (either bullish or bearish) rumour. This rumour causes a market overreaction whereby the price overshoots the fair value of the stock. Van Bommel finds that the rumourmonger has the opportunity to profit twice: first as she trades in the direction of her information and secondly when she trades in the opposite direction knowing the effect of the rumour to be overshooting (2003, p.1500). Van Bommel's model demonstrated that this strategy imposes a moral hazard cost on rumourmongers: If followers understand that an informed trader has incentive to cheat, they will no longer take notice of rumours (2003, p.1513). An analysis of repeated games shows that opportunistic manipulators will refrain from bluffing or cheating because they may lose their reputation and their ability to manipulate prices (2003, p.1513).

The advent of the Internet has dramatically increased the opportunities to spread market rumours. Van Bommel noted that the internet has proven a very productive incubator of rumours in online chatrooms, newsgroups and message boards (2003, p1500). Of course rumours can still be spread the old fashioned way word of mouth, newsletters and financial broadsheets. While increased dissemination of price-sensitive information is a positive development for market efficiency, this new media also present opportunities for manipulators. Manipulators can anonymously add their own strategically biased messages in online stockbroking forums.

Tumarkin and Whitelaw (2001) undertook to empirically test the ability of manipulators to impact markets through online forums. They examined the relationship between internet message board activity and abnormal stock returns and trading volumes. Perhaps surprisingly, they found returns were statistically insignificant as compared with message board activity (2001, p.51). Their findings 
contradict anecdotal evidence that stock manipulation via online message boards is rampant and widespread.

Despite Tumarkin and Whitelaw's study, concerns about manipulative rumours have grown and recently peaked in the Global Financial Crisis. The Corporations and Markets Advisory Committee (2009) has observed that "when markets fall rapidly or go through a stage of volatility and uncertainty, the potential for market manipulation increases'. The Corporations and Markets Advisory Committee noted that in late 2008, the financial crisis gave rise to concerns in Australia and other markets that short sellers were using rumours to drive down the price of particular stocks'(2009, p.95). The concerns around rumourtage were one reason why ASIC imposed the ban of short-selling of financial stocks. ASIC also instigated 'Project Mint', an investigation into the impact of false rumours and manipulation. Despite the persistent and widespread anecdotal claims of informationbased market manipulation in the worst global market collapse since 1929, which purportedly justified the imposition of the longest short-selling ban in the developed world, Project Mint famously only procured one conviction before being shelved (Verrender 2009). This reflects more the prosecutorial and evidentiary challenges of successfully convicting manipulations and not the complete absence of substantive rumourtage in the market.

\section{Empirical Investigation of the HKSE}

This is the first study to examine the HKSE utilising a comprehensive sample of actual manipulation cases. By using an event study method, this study seeks to establish whether: (a) manipulators on the HKSE are able to alter prices and profit from these changes; and (b) examine the impact of manipulation on measures of market efficiency. The empirical implications of this study of the HKEX act as a warning to all organised exchanges about the potential harm of market manipulation.

The HKEX was chosen as a comparable stock exchange to the ASX in terms of market capitalisation, trading mechanisms and sophistication. The trading and legal institutional framework of the HKSE is broadly comparable to that the ASX, which suggests that the empirical implications of manipulation on the HKEX may be applicable to other order-driven exchanges, such as the ASX and Chi-X. Utilising these results, this study provides a rationale for why market manipulation must continue to be prohibited by law and robustly prosecuted to deter future misconduct.

\subsection{Institutional Framework}

The HKSE is Asia's second largest stock exchange in terms of market capitalisation and the fifth largest in the world. According to the World Federation of Exchanges (2013), the HKSE, as at July 2013, had 1,531 listed companies and a total market 
capitalisation of \$HK 21,509.4 billion or \$AUD 3,012.5 billion. For comparison, the ASX at July 2013 has a market capitalisation of \$AUD1,421.4 billion and 2,184 listed companies (World Federation of Exchanges 2013).

The HKEX is an order-driven market. Stocks are predominantly traded during the continuous trading session that lasts from 9:30am to $4 \mathrm{pm}$. During a continuous trading session, the Third Generation Automatic Order Matching and Execution System ('AMS/3') matches buy and sell orders submitted by exchange participants by the specified price and order size.

The legislation prohibiting share market manipulation in Hong Kong is the CAP 571 Securities and Futures Ordinance (Hong Kong) ('SFO'). The SFO introduced the concept of 'market misconduct' to the Hong Kong regulatory regime and replaced the more constrained categories of manipulation that existed in the superseded CAP 333 Securities Ordinance (Hong Kong) Pt XII. These old provisions have been described as 'the most difficult part of the ordinance, due largely to the inherent weakness of statutory language to tackle a sophisticated and complex area of stock market activities' (Au 1988).

Market Misconduct is defined in section 245 of the SFO as including insider dealing, false trading, price rigging, disclosure of false or misleading information and stock market manipulation. The notion of 'market misconduct' is roughly based on the equivalent provisions in Australian corporate law (Arjunan 2003).

Section 278(1) of the SFO defines stock market manipulation as involving two or more transactions that aim to increase, decrease or maintain market prices with an intention to induce others to trade. This formulation of manipulation incorporates several problematic issues. First it does not capture single transactions accompanied by a fraudulent/manipulative intent, however objectionable. Secondly, proving intent to induce creates conceptual programs in distinguishing manipulation from legitimate trades. Indeed, it could be suggested that the object of every bid or ask may be seen as intending to change the price to induce another to trade. The maximum penalty for an indictable breach of the anti-manipulation provision is, per s303 of the SOF, a fine of \$HK 10,000,000 and imprisonment for up to 10 years.

The responsible Hong Kong regulator is the Securities and Futures Commission ('SFC') which was modelled on the Australian Securities Commission, the precursor to ASIC. The SFC's statutory objectives in section 4 of the SFO include maintaining and promoting the fairness, efficiency, competitiveness, transparency and orderliness of the securities and futures industry as well as minimizing crime and misconduct. 


\subsection{Description of Data}

This event study examines a comprehensive set of market manipulation cases that were successfully prosecuted by the SFC. These 40 cases of manipulation occurred between April 1996 to March 2009. The dataset extends back before the enactment of CAP 333 Securities Ordinance (Hong Kong).

The unique sample of cases includes a considerable amount of market data obtained from the Securities Industry Research Centre of Asia-Pacific (SIRCA). This intraday data includes the time to the second of each trade, bid, ask, volume and price. In examining this data, this study adopts the market microstructure analyst method by using volumes and the bid-ask spread as proxies for information asymmetry to examine the strategy behaviour of market particulars as they react to manipulation.

There are several noteworthy caveats to this dataset. The data only includes cases of manipulation involving shares and does not extend to cases of manipulation of other financial products. This excludes from the some dataset some prominent cases of manipulation like the Court of Appeal decision of HKSAR v Fu Kor Kuen Patrick [2011] 1 HKLRD 655, CACC 179/2010 that involved manipulation of derivative warrants issued by Macquarie Bank Ltd. In that case, the traders traded derivative instruments between each other, back and forth to qualify for commission rebates provided by Macquarie. Recently on appeal in Fu Kor Kuen v. HKSAR (FACC No. 4 of 2011, May 24, 2012) the Final Court of Appeal overturned this conviction finding that the trading for rebates was not undertaken for the purpose of creating a false or misleading appearance of active trading or with respect to the market for securities.

Secondly the data only includes historical cases where the SFC brought a successful enforcement action. This omits potential cases where manipulation; (a) occurred but was undetected, or (b) was detected but the SFC did not bring a successful enforcement action. This investigation therefore shares the same weakness of the seminal work of Aggarwal and Wu (2006). The data, and therefore the results, may be said to only apply to 'poor' manipulators in the sense that they were caught.

The cases in the data set were all trade-based manipulation, predominantly involving thinly traded stocks. Almost all cases involved manipulation to force a stock price higher, often by placing bids and trading near the close at successively higher prices. Only one case within the dataset involved a manipulator attempting to stabilise a market price. This was the case of Han Sze Chao (SFC, 2007) where the SFC found Han caused small and/or single board lots to be placed to stabilise the price of shares in Fortuna International Holdings Ltd, effectively pegging the price of 
those shares at $\$ \mathrm{HK} 0.30$ (SFC, July 2004). No case involved trying to push prices lower.

The price impact on the manipulated shares in the dataset was reported as an increase anywhere between $5 \%$ and $150 \%$. In all except two cases, the plaintiff(s) pleaded guilty and received fines/suspended sentences. The first 'not guilty' case was Securities \& Futures Commission v Choi Wai Zak [2003] 1 HKC 30 HCMA 264/2002. The case involved two defendants charged with creating a false appearance of active trading the shares of the Hong Kong Parkview Group Ltd. This was the only case involving section 135 of the Securities Ordinance (Hong Kong) cap 333 that was appealed. Choy and Yuen were convicted of trading the shares in tranches with each trade at a higher price that the previous ones, giving the impression of a rising price. These trades involved no change in beneficial ownership. At [19] the Court imposed a sentence of 8 months and 4 months respectively.

The second case where the defendants pleaded 'not guilty' case was HKSAR v Chan Chin-yuen and others (2008) DCC683/2008. This is the most criminally serious case in the dataset and is the largest case of market manipulation in the history of the HKSE. The four defendants conspired to create a false appearance market for the shares of the Asia Standard Hotel Group Ltd ('ASH'). They traded ASH shares among themselves with their trades constituting $60.2 \%$ of all ASH shares bought in the relevant period. The effect of their false trading ramped up the company's market capitalisation by HK $\$ 4$ billion. The pattern of trading led to the irresistible inference that it was not genuine trading but trading designed to manipulate the shares in ASH by creating a false impression of demand. If such activities were undeterred, the court found they would have undermined the fairness of the HKEX. Accordingly, the court at [41] imposed sentences of imprisonment ranging between 26 months to 30 months.

As previously stated, an indictable conviction of market misconduct enables a prison sentence of up to 10 years to be imposed per s.303 of the SFO. Mitigating factors aside, this was the most serious case of market manipulation criminality in Hong Kong's history and the imprisonment sentences in no way reflected anywhere near the maximum as provided by the SFO. One possible reason for this is that courts simply do not consider market manipulation to have an objective level of serious criminality in order to justify the imposition of more harsh penalties.

\subsection{Preparation of Data}

To empirically test how the market responds to manipulation, this study uses a robust econometric tool called an 'event study'. Event studies were originally used to test the association between company earnings and market prices (Ball \& Brown 1968). Since then, event studies have been widely used by U.S. courts to examine the impact of market manipulation (Leas 1974; Scwert 1981). Fischel stated that the use of event 
studies enables a determination of whether false information caused a security to trade at an 'artificially high or low level' (1982, p.17). Macey, Miller, Mitchell and Netter noted that when an 'event study methodology shows a fraudulent event has a statistically significant effect on the price of a firm's securities, courts are justify in presuming reliance under the fraud-on-the-market theory' (1991, p.1018).

The dataset of intraday trading activity was first summarised into daily measures. The 'event' date was designated as the date of the manipulation. In order to examine the ability of manipulation to move market prices, returns are used.

- Return: the percentage capital gain of holding a share price over two consecutive days. The measure reflects share price movements.

$$
\text { Return }=\frac{\text { Share } \text { Price }_{1}-\text { Share } \text { Price }_{0}}{\text { Share } \text { Price } t_{0}}
$$

To examine the impact of manipulation and other variables, this study uses a number of explanatory variables:

- The bid-ask spread is the difference between the close of trade asking price and the close of trade bid price. The bid-ask spread has been identified as an important measure of information asymmetry, liquidity and efficiency.

Quoted BAS $=$ Ask Price - Bid Price

- Volume: the total amount of shares traded on a particular day.

- Proportional Bid-Ask Spread: The proportional bid-ask spread is used as a control for variations in stock prices across stocks and over time.

PBAS $=\frac{\text { askprice }- \text { bidprice }}{(\text { askprice }+ \text { bidprice }) / 2}$

- Volatility or Risk: is calculated by taking the logarithm of the proportion of the high and the low price on each day for each stock.

$$
\text { Volatility }=\ln \left[\frac{\text { High }}{\text { Low }}\right]
$$


- Dichotomous Variable: the dichotomous variable takes on the value of 0 before the event date and 1 after the event date.

$$
D_{t}=\left\{\begin{array}{l}
\mathbf{0} \text { if observation falls before event date } \\
1 \text { otherwise }
\end{array}\right.
$$

In order to examine the effects of manipulation on the market, a time period around the event must be identified. This study uses a time period of 200 days. This means that the cases have been examined over the prior 100 days before the manipulation and 100 days after. In order to allow for comparison of manipulation across the cases, cross-sectional averages were calculated for each relative day. These averages of the explanatory variables are used as measure of the buying and selling interests of the market. To avoid 'infection' by unrelated or confounding events, data from days of a company announcement have been removed.

$$
T=-100,100
$$

The descriptive statistics used in univariate analysis may be used to compare the state of the market before manipulation to the market after manipulation. By examining each variable individually, this analysis can demonstrate manipulation's direct impact on the market. To test the significance of the variables to a control period, a t-test is used. A test-statistic highlights how far away the variables results, $\bar{X}$, are from the hypothesised control value, ${ }^{\mu}$, scaled by the standard deviations of the mean, $\sigma_{\bar{x}}$. Where the t-statistic is a large, the observed value has been greatly impacted by manipulation. Large t-statistics over 2 as a rule-of-thumb are said to be statistically significant.

$$
t=\frac{(\bar{X}-\mu)}{\sigma_{\bar{X}}}
$$


Table 3-1: Cross-Sectional Average Sample.

Time series are calculated for each variable being bid-ask spread, proportional bid-ask spread, returns, risk and volume for 100 days before and after the manipulation date.

\begin{tabular}{llllll}
\hline $\begin{array}{l}\text { Relative } \\
\text { Date }\end{array}$ & BAS & PBAS & Returns & Risk & Volume \\
\hline-100 & 0.013502 & 0.078020 & -0.008590 & 0.023745 & 1145411 \\
-99 & 0.026580 & 0.096396 & -0.011429 & 0.027896 & 1895708 \\
-98 & 0.015782 & 0.099850 & -0.012313 & 0.020184 & 1183024 \\
\hline & & & & & \\
\hline-2 & 0.014951 & 0.108525 & 0.000213 & 0.100705 & 1081180 \\
-1 & 0.029201 & 0.173075 & -0.020344 & 0.073705 & 1208936 \\
$\mathbf{0}$ & $\mathbf{0 . 0 5 4 1 9 9}$ & $\mathbf{0 . 2 1 2 8 5 0}$ & $\mathbf{0 . 0 0 8 2 7 6}$ & $\mathbf{0 . 1 0 0 4 7 5}$ & $\mathbf{5 6 9 0 0 0}$ \\
1 & 0.053050 & 0.153306 & -0.018381 & 0.047112 & 607018 \\
2 & 0.048017 & 0.120441 & 0.009574 & 0.066439 & 549833 \\
\hline 97 & & & & & \\
\hline 98 & 0.024959 & 0.189253 & 0.006363 & 0.043517 & 3395597 \\
99 & 0.021105 & 0.128917 & 0.014883 & 0.086382 & 1462211 \\
100 & 0.019354 & 0.117870 & 0.000973 & 0.030397 & 1790333 \\
\hline
\end{tabular}

By blending univariate testing with regression analysis this study will employ a robust method of examining the market reaction to manipulation. To test the descriptive results, this investigation will run the following regressions.

\section{$\underline{\text { Regression Set 1: }}$}

$B A S=\alpha+\beta_{1} D_{t}+\varepsilon_{t}$

$P B A S=\alpha+\beta_{1} D_{t}+\varepsilon_{t}$

$B A S=\alpha+\beta_{1} D_{t}+\beta_{2}$ Volume $_{t}+\beta_{3}$ Volatility $_{\mathrm{t}}+\varepsilon_{\mathrm{t}}$

$P B A S=\alpha+\beta_{1} D_{t}+\beta_{2}$ Volume $_{t}+\beta_{3}$ Volatility $_{t}+\varepsilon_{t}$

These regression equations will be used to test how statistically significant each explanatory variable is to the BAS and PBAS. $\beta$ represents each independent variable's coefficient. $\alpha$ is the significance level and $\varepsilon_{\mathrm{t}}$ a measure of error.

Equations 3.7 and 3.8 regress the BAS and PBAS onto the dummy variable. Using the dichotomous variable as the only explanatory variable demonstrates the extent to which manipulation affects the spread. It is important to note why both the bid-ask spread and the proportional bid-ask spread are used. Unlike the bid-ask spread, the proportional bid-ask spread reflects the relative spread. The PBAS has a higher explanatory power because it potentially provides more accurate results 
reflecting the relative difference in bids and asks, not just the raw spread. A simple example is instructive to demonstrate the difference between the BAS and PBAS is useful. For a bid/ask of $\$ 1000 / \$ 998$ and $\$ 4 / \$ 2$ the BAS is simply 2. Yet the relative spread or PBAS is .002 for the first example and .67 for the second.

Equations 3.9 and 3.10 introduce other variables to determine the degree to which the volume and volatility relates to the spread. While this may yield insightful results, the inclusion of these independent variables also increases the risk that the regression will identify random 'noises' that are unrelated to the manipulation.

The spread is not the only measure of information asymmetry. Recall that Easley and O'Hara (1987, p.70) have suggested that market liquidity has both a price dimension (spread) and a quantity dimension (volume). Hence the second regression set will use market volume as the dependant variable with the dummy, spread and volatility as explanatory variables.

\section{Regression Set 2:}

Volume $=\alpha+\beta_{1} D_{t}+\varepsilon_{t}$

Volume $=\alpha+\beta_{1} \mathrm{D}_{\mathrm{t}}+\beta_{2} \mathrm{BAS}+\beta_{3}$ Volatility $+\varepsilon_{\mathrm{t}}$

Volume $=\alpha+\beta_{1} \mathrm{D}_{\mathrm{t}}+\beta_{2} \mathrm{PBAS}+\beta_{3}$ Volatility $+\varepsilon_{\mathrm{t}}$

Both sets of regressions' statistical significance will be examined by reference to $p$ values. The $p$-value is the probability of obtaining a t-statistic at least as extreme as the one actually observed when assuming manipulation has no effect on the market, being the null-hypothesis. If the $p$-value is less than the significance level $(10 \%, 5 \%$ or $1 \%$ ) the variable is said to be statistically significant to the independent variable. The smaller the p-value, the more strongly the test rejects the null hypothesis. For example, a p-value of .05 or less rejects the null hypothesis at the 5\% level. Lastly, it is noteworthy that returns are not being used in the regressions as an explanatory variable. This is because risk and return are highly correlated variables. Inclusion of returns would mean the results would display multicollinearity.

\subsection{Univariate Results}

The univariate results indicate that manipulators have a discernible impact on market prices, the spread, volume and overall market risk. Firstly, average market variables are compared with those present at the manipulation date. Market measures on the day of manipulation are strikingly at variance with the pre, post and total averages. 
Table 3-2: Mean Statistics for a 200 day event period

This table reports the descriptive averages for the 40 manipulated stocks. It also provides in bold, the market measures on the precise day of manipulation.

\begin{tabular}{llllll}
\hline & $\begin{array}{l}\text { Bid-Ask } \\
\text { Spread }\end{array}$ & $\begin{array}{l}\text { Proportional Bid-Ask } \\
\text { Spread }\end{array}$ & Return & Risk & Volume \\
\hline Pre-event mean & 0.0228 & 0.1137 & -0.0008 & 0.0443 & 1341298 \\
Post-event mean & 0.0243 & 0.1337 & -0.0006 & 0.0489 & 1355646 \\
Total mean & 0.0236 & 0.1237 & -0.0007 & 0.0466 & 1348508 \\
\hline Event & $\mathbf{0 . 0 5 4 2}$ & $\mathbf{0 . 2 1 2 9}$ & $\mathbf{0 . 0 0 8 3}$ & $\mathbf{0 . 1 0 0 5}$ & $\mathbf{5 6 9 0 0 0}$ \\
\hline
\end{tabular}

Table 3-2 demonstrates higher BAS, PBAS, return and risk associated wit the date of actual manipulation. The large widening of the spreads indicates information leakage as market participants start requiring increased compensation for fear of trading with a suspected manipulator. The results strongly suggest that the presence of a manipulator harms market efficiency by increasing the cost of trading.

The event period was a time of negative growth with the pre, post and total returns being negative. Yet on the day of manipulation, returns and therefore prices increased. Event day returns are 141\% higher than the previous day, up $114 \%$ on the pre-event mean and $129 \%$ above the total average. This appears to indicate that despite negative market sentiment, the manipulators have been able to raise prices to 'artificial' levels.

Lastly it is observed that the trading volume on the date of manipulation is significantly lower than the averages. This intuitively suggests that manipulation is more successful in low volume markets as the distortive effect of manipulative trades on prices is likely to be amplified. This finding is consistent with Thel (1994) and also Aggarwal and Wu's study (2006) regarding the increased likelihood of successful manipulation associated with low liquidity/volume stocks.

\subsubsection{Market Measures before and after manipulation}

A comparison between pre-event and post-event descriptive statistics is useful to understand the total impact of manipulation. Manipulation does not only affect the market on the 'event' date but throughout the following 100 days as the market adjusts to the presence of a manipulator. Table 3-3 outlines the descriptive statistics for the pre-event and post-event periods. Manipulation's lasting impact is seen in increased averages for all market measures.

The mean bid-ask spread has widened by $65 \%$ in the post-event period. The median, maximum and minimum have also increased. Figure 1 shows two significant spikes in the average bid-ask spread around the manipulation date. The widening of the BAS reflect the rational response of market participants concern about trading 
with a manipulator. Interestingly the existence of two spikes may suggest manipulators are playing the market with mis-information. The subsequent narrowing and then re-widening of the BAS may suggest manipulators are fooling participants into reacting too early and profiting from subsequent corrections. The average postevent PBAS is up by $18 \%$. The median, max, min and standard deviation have all also increased. Figure 2 shows the PBAS spikes at time 0. Further average market risk in the post-manipulation period has risen by $10 \%$. The kurtosis also increased dramatically from 1.4 to 3.3 .

Lastly the volume figures all show increased measures in the post-event period. The increased kurtosis (up from 5.33 to 13.26) reflects upward trends in volume traded in the post-event period. Figure 3 highlights that the manipulation (time 0 ) occurred at a time of exceptional low volume.

\section{Figure 1: Bid-Ask Spread Graph}

This figure depicts the average bid-ask spread for the 40 stocks that were manipulated on the HKEX from 1996 to 2009. Day 0, is the date manipulation date.

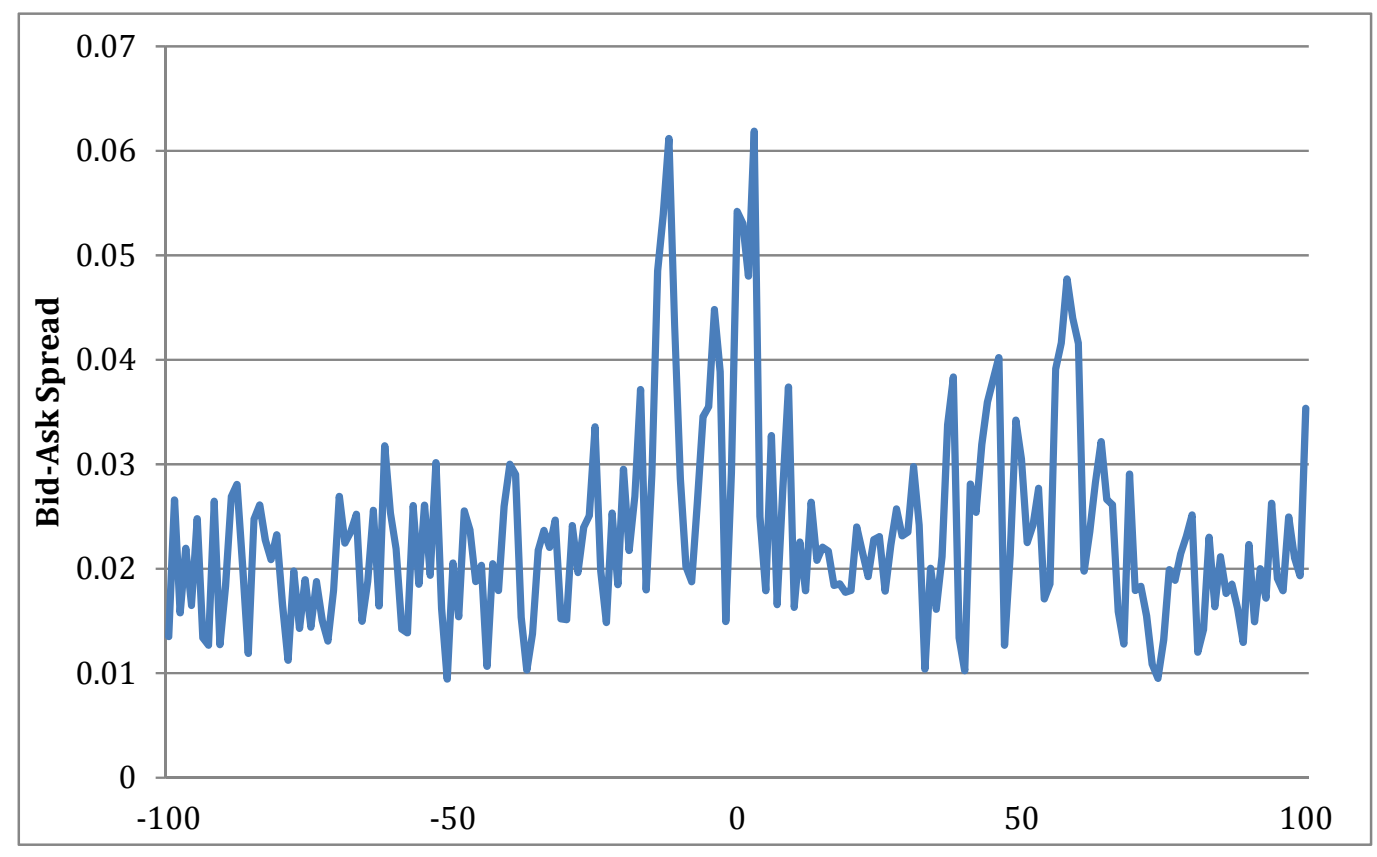




\section{Table 3-3: Descriptive Statistics for a 200 day event period}

This table reports the descriptive statistics (bid-ask spread, proportional bid-ask spread, risk, volatility (risk) and volume,) for the 40 manipulated stocks. For each variable, the table reports the mean, median, maximum, minimum, standard deviation, skewness and kurtosis for the 100 days before and after the manipulation date

\begin{tabular}{|c|c|c|c|c|c|c|c|c|c|c|}
\hline & \multicolumn{2}{|c|}{ Bid-Ask Spread } & \multicolumn{2}{|c|}{$\begin{array}{l}\text { Proportional } \\
\text { Bid-Ask Spread }\end{array}$} & \multicolumn{2}{|l|}{ Return } & \multicolumn{2}{|c|}{ Volatility } & \multicolumn{2}{|l|}{ Volume } \\
\hline & Before & After & Before & After & Before & After & Before & After & Before & After \\
\hline Mean & 0.0228 & 0.0243 & 0.1137 & 0.1337 & -0.0008 & -0.0006 & 0.0443 & 0.0489 & 1341298 & 1355646 \\
\hline Median & 0.0218 & 0.0221 & 0.0591 & 0.1294 & -0.0014 & -0.0013 & 0.0378 & 0.0450 & 1094633 & 1146066 \\
\hline Maximum & 0.0612 & 0.0619 & 0.1957 & 0.2129 & 0.0545 & 0.0388 & 0.1158 & 0.1455 & 5960857 & 7681257 \\
\hline Minimum & 0.0094 & 0.0095 & 0.0094 & 0.0619 & -0.0428 & -0.0363 & 0.0162 & 0.0104 & 128778 & 265628 \\
\hline St Dev & 0.0099 & 0.0101 & 0.0500 & 0.0296 & 0.0162 & 0.0138 & 0.0211 & 0.0216 & 965515 & 1059783 \\
\hline Skewness & 1.5492 & 1.3694 & 0.4159 & 0.4145 & 0.3672 & 0.4454 & 1.2110 & 1.3835 & 1.8934 & 2.9605 \\
\hline Kurtosis & 2.7195 & 2.0557 & -1.2223 & 0.0346 & 1.6167 & 1.0987 & 1.4702 & 3.3101 & 5.3349 & 13.2698 \\
\hline
\end{tabular}




\section{Figure 2: Proportional Bid-Ask Spread Graph}

This figure depicts the average proportional bid-ask spread for the 40 stocks that were manipulated on the HKEX from 1996 to 2009. Day 0, is the date manipulation date.

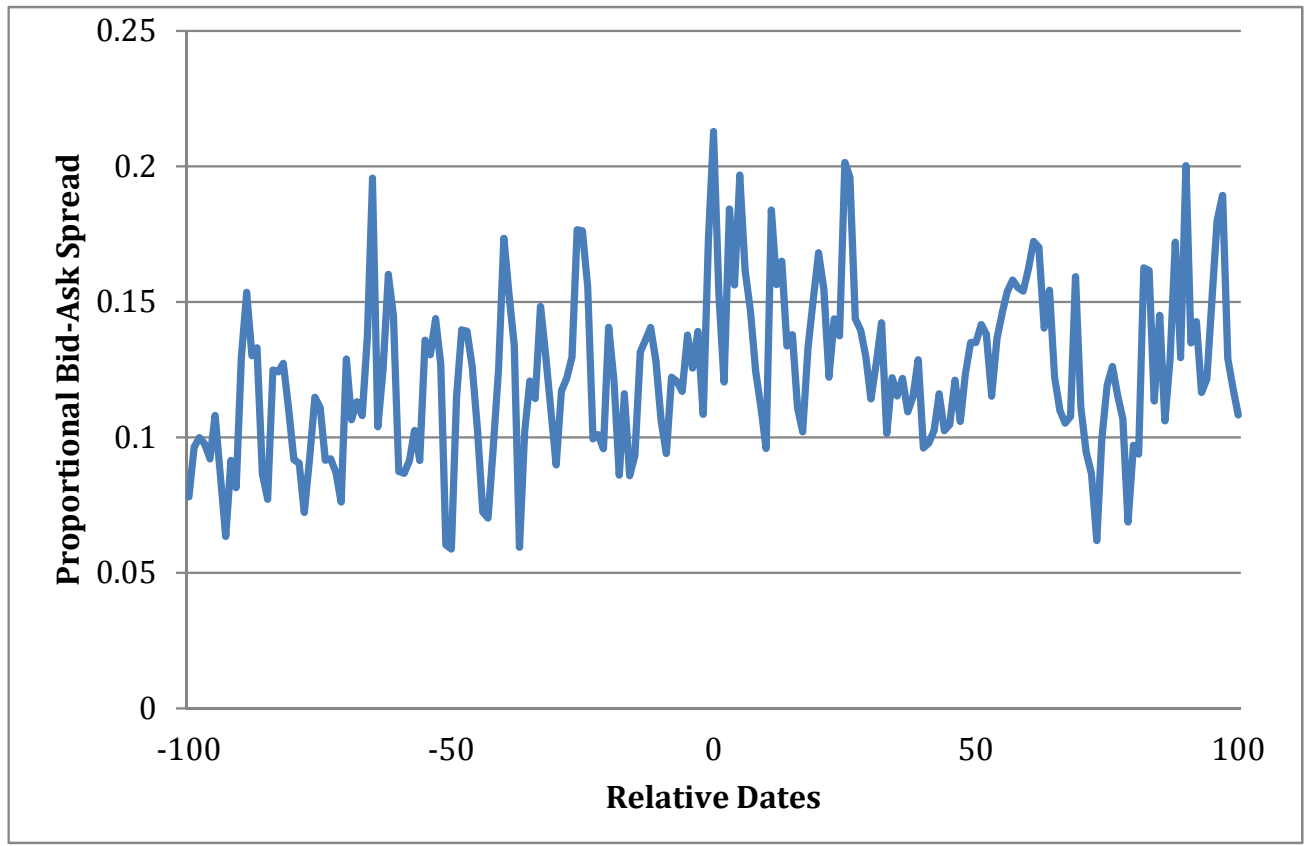

\section{Figure 3: Market Volume Graph}

This figure depicts the volume traded for the 40 stocks that were manipulated on the HKEX from 1996 to 2009 . Day 0 , is the date manipulation date.

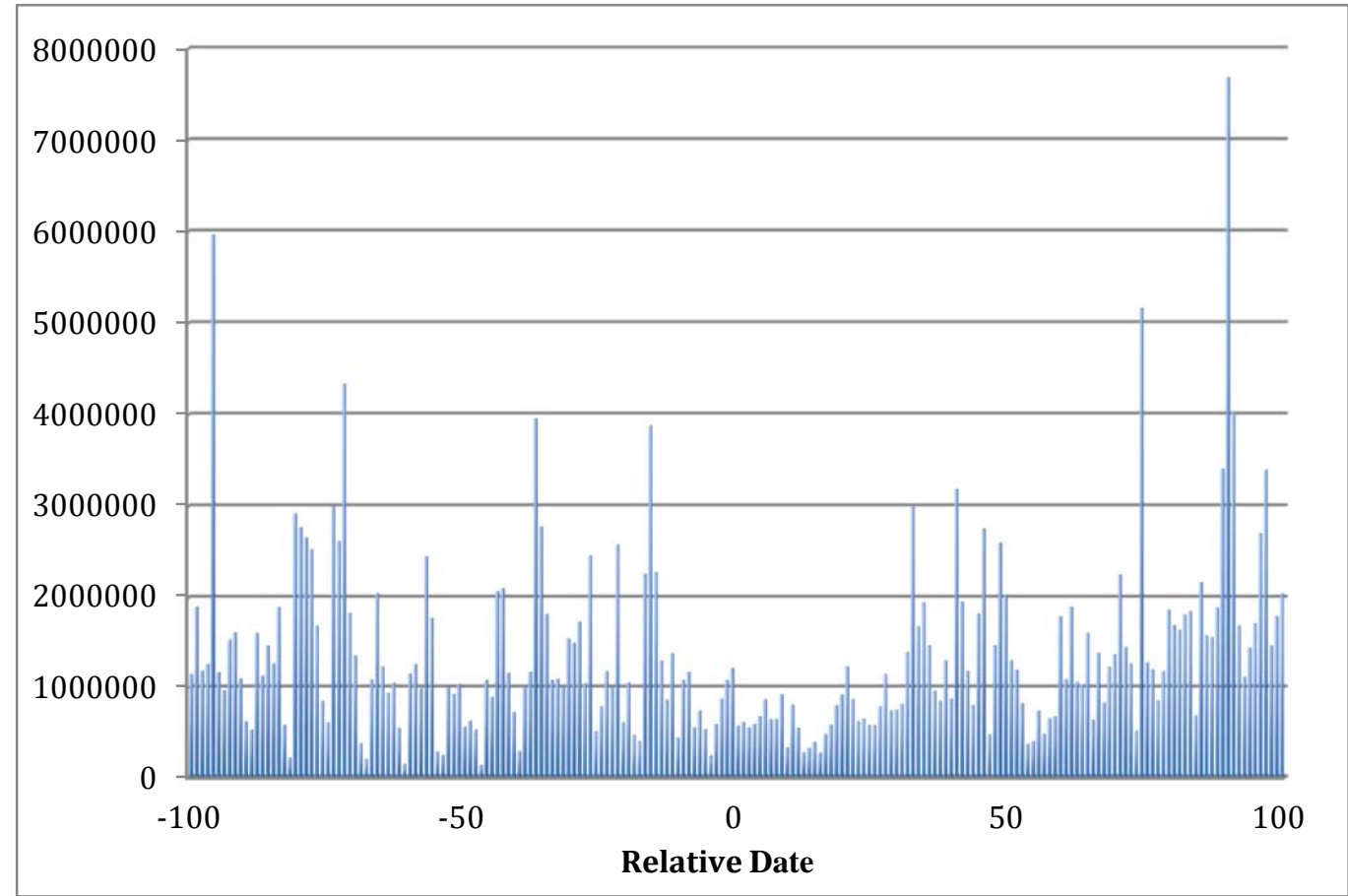




\subsubsection{Examination of Profitability of Manipulation}

To investigate whether markets display asymmetric price responses, further analysis of returns is required. The whole plethora of intraday buying and selling transactions must be examined to determine the relative returns. Relative returns per transaction for the pre and post-event period will highlight whether manipulators were able to move market prices to create an illegitimate profit.

Recall that Fischel and Ross (1991, p.518) have claimed that trade-based market manipulation is completely self-deterring as manipulators are unable to sell at the artificially high prices they have created. These authors (1991, p.519) suggest that any attempt to sell shares at an artificially high level, particularly in large quantities, will be unsuccessful as buying and selling have symmetric price impacts. The profitability of manipulation is also relates to how large a quantity may be transacted at artificially high prices. Easley \& O'Hara have posited that trade size introduces an adverse selection risk (1987, p.70). While Easley \& O'Hara (1987) were discussing insider trading, the same quantity bias may be true for manipulators. When manipulators have pushed share prices to artificial values, they would seek to trade in as large a quantity as possible before market prices return to fall back down to equilibrium. This theory suggests that market participants would raise spreads for large trades given the rational fear of trading with a manipulator.

Table 3-4 investigates the potential profitability of trade-based manipulation. The 40 case dataset was divided into quartiles with quartile 1 representing the smallest $25 \%$ of trades and quartile 4 representing the largest $25 \%$ of trades. The relative returns to both selling and buying transactions were calculated, as were tstatistics. Table 3-4 show that returns increased dramatically in the post-event period for all four quartiles. This translates to a price impact as higher returns imply higher prices and lower negative returns imply lower prices. Increases in returns were higher than increases in sales. The higher purchase side returns provide empirical support to the asymmetric price responses suggested by Allen \& Gorton (1992). Trade-based manipulation may be possible and profitable merely by buying with a relatively large effect and selling with a lesser effect with $75 \%$ of all trade sizes. This means a manipulator can buy with large effect on prices and sell with a smaller effect. The existence of profitable manipulation suggests some information asymmetry on the HKSE. Figure 4 has shown that spreads increased around time 0 . This suggests that market participants were aware of the possibility of manipulation. Yet the increase in the cost of trading was not commensurate to stop profitable price manipulation. Returns were statistically significant for all quartiles, even the largest $25 \%$ of trades. Manipulators were likely able to sell at the high levels they engineered, for profit. Had ordinary investors been truly certain about the presence of manipulators, the spread would have risen to a level that would have made manipulation unprofitable. 


\section{Table 3-4: Buying and Selling Returns by Trade Size}

This table reports the returns data for both the buying and selling transactions. The returns are sorted into quartiles with the $1^{\text {st }}$ quartile representing the smallest $25 \%$ of trades by volume and quartile 4 representing the largest $25 \%$ of trades. The negative figures for returns on the sell side reflect positive real returns for the sellers. The return percentage is negative only because the shares were sold and not bought. Thus the negative figure represents the loss to the buyer who trades with the seller. All quartile results are statistically significant, producing high t-statistics. ${ }^{*}$ connotes statistical significance.

\begin{tabular}{|c|c|c|c|c|c|c|c|c|c|}
\hline \multicolumn{2}{|c|}{ Quartile 1} & \multicolumn{2}{|c|}{ Quartile 2} & \multicolumn{2}{|c|}{ Quartile 3} & \multicolumn{2}{|c|}{ Quartile 4} & \multicolumn{2}{|l|}{ All } \\
\hline Buy & Sell & Buy & Sell & Buy & Sell & Buy & Sell & Buy & Sell \\
\hline \multicolumn{10}{|l|}{ Panel A - Pre-period } \\
\hline $17.39 \%$ & $-6.10 \%$ & $14.77 \%$ & $-7.10 \%$ & $17.82 \%$ & $-8.40 \%$ & $23.69 \%$ & $-13.60 \%$ & $17.77 \%$ & $-8.20 \%$ \\
\hline \multicolumn{10}{|l|}{ Panel B - Post-period } \\
\hline $25.05 \%$ & $-17.40 \%$ & $26.33 \%$ & $-14.70 \%$ & $28.24 \%$ & $-16.10 \%$ & $33.85 \%$ & $-22.30 \%$ & $27.94 \%$ & $-17.60 \%$ \\
\hline \multicolumn{10}{|l|}{$\%$ change } \\
\hline $7.66 \%$ & $-11.30 \%$ & $11.56 \%$ & $-7.60 \%$ & $10.42 \%$ & $-7.70 \%$ & $10.16 \%$ & $-8.70 \%$ & $10.17 \%$ & $-9.40 \%$ \\
\hline \multicolumn{10}{|l|}{ t-statistic } \\
\hline $13.4 *$ & $-12.6^{*}$ & $11.2 *$ & $-16.2 *$ & $14.1 *$ & $-16.3 *$ & $12.4 *$ & $-17.8^{*}$ & $12.9 *$ & $-11.2 *$ \\
\hline
\end{tabular}




\subsection{Regression Results}

\subsubsection{First Regression}

The first regression set produces highly significant results. The results examine the statistical relationship between the dummy variable (denoted as 'change' in table 35), volume and risk on the spreads.

Equation 3.7 regresses the BAS onto the dummy variable, which represents the dataset change post manipulation. Regressing just the dummy variable is useful as it isolates the effect of manipulation on the BAS. The positive coefficient of .0015 suggests manipulation does increase the BAS. The result is not highly significant however having a p-value above the $10 \%$ significance level. A dramatically more statistically significant result is found by regressing the PBAS onto the dummy. With a p-value of less than the $1 \%$ significance level, this suggests with $99 \%$ confidence that a higher PBAS is associated with manipulation. By isolating the effect of market manipulation on the PBAS, this regression represents a powerful finding.

Equation 3.9 also shows significant results. The positive coefficients for the volume and volatility variables suggest that the BAS increases when these variables increase. The volume coefficient is a negative figure that is unobservable to 4 decimal places in Table 3-5. The volume coefficient is a small figure. The figure must be small because it needs to be multiplied by the very large volume figure to arrive at the BAS, which itself is small value. The actual value of the figure is -0.000000002 . This negative volume coefficient shows an inverse relationship between spread and amount traded. Both the volume and volatility results are statistically significant at the $1 \%$ and $5 \%$ levels respectively. As in 3.7 , the dummy variable is not statistically significant with the spread.

Equation 3.10 provides an extremely statistically significant result. The dummy variable and volatility are strongly statically significant at the $1 \%$ level. The volume is significant at the $10 \%$ level. This regression demonstrates with exceptionally high certainty that manipulation coincides with higher relative spreads, increased risk and smaller trading volume. This is a significant finding.

The first set of regressions highlights the explanatory power of the PBAS over the BAS. The increased relative spread being associated with manipulation confirms the suggested models in the literature where market participants build in an informational risk into spreads. Manipulation then, appears to increase transaction costs and also reduces market liquidity and efficiency. 


\subsubsection{Second Set of Regressions}

The second set of regressions uses volume as the dependent variable. Large coefficients were produced reflecting the relative size of volume data as compared with the data of the independent variables. The results do not find a level of statistical significance. Equation 3.11 regresses the volume onto the dummy variable. The resulting $p$-value is .9202 which suggests manipulation is not statistically significant with trading volume. Similarly the dummy explanatory variable in equations 3.12 and 3.13 are not significant.

The second set of regressions finds statistically significant relationships between the volume and the explanatory variables except for the dummy. Equation 3.12 and 3.13 provides negative coefficients for volatility suggesting that when stocks are more risky there is less trading volume. Volatility is significant at the $10 \%$ level. The BAS and PBAS also provide negative coefficients, which suggests that wider spreads result in lower trading volumes. The Volume/BAS relationship is highly significant at the $1 \%$ level. The volume/PBAS relationship is significant at $10 \%$ level. The worryingly implication of these finding is that market manipulation is possible both when volumes traded are high and low. 
Table 3-5: Multivariate Regression Results for a 200 day event period

This table reports results from the regressions, equations 3.9 to 3.15 over 200 days. The regressions are based on the 40 stock cases of market manipulation on the Hong Kong Stock Exchange. The 'change' explanatory variable represents the independent variable regressed onto the dichotomous value. ***,**,* denotes statistical significance at $1 \%, 5 \%$ and $10 \%$ levels respectivel

\begin{tabular}{|c|c|c|c|c|c|c|}
\hline & Intercept & Change & Volume & Volatility & BAS & PBAS \\
\hline \multicolumn{7}{|c|}{ First Set of Regressions } \\
\hline \multicolumn{7}{|c|}{ BAS (Control) } \\
\hline Equation 3.7 & 0.0228 & 0.0015 & & & & \\
\hline$P$-value & $<0.0001^{* * *}$ & 0.2641 & & & & \\
\hline \multicolumn{7}{|l|}{ PBAS (Control) } \\
\hline \multirow[t]{2}{*}{ Equation 3.8} & 0.1137 & 0.0201 & & & & \\
\hline & $<0.0001^{* * *}$ & $<0.0001^{* * *}$ & & & & \\
\hline \multicolumn{7}{|l|}{ BAS } \\
\hline \multirow[t]{2}{*}{ Equation 3.9} & 0.0221 & 0.0012 & 0.0000 & 0.0760 & & \\
\hline & $<0.0001^{* * *}$ & 0.3622 & $0.0024 * * *$ & $0.0149 * *$ & & \\
\hline \multicolumn{7}{|l|}{ PBAS } \\
\hline \multirow[t]{2}{*}{ Equation 3.10} & 0.1026 & 0.0184 & 0.0000 & 0.3613 & & \\
\hline & $<0.0001^{* * *}$ & $<0.0001^{* * *}$ & $0.0568 *$ & $0.0001^{* * *}$ & & \\
\hline \multicolumn{7}{|c|}{ Second Set of Regressions } \\
\hline \multicolumn{7}{|c|}{ Volume (Control) } \\
\hline \multirow[t]{2}{*}{ Equation 3.11} & 1341298 & 14348 & & & & \\
\hline & $<0.0001^{* * *}$ & 0.9202 & & & & \\
\hline \multicolumn{7}{|l|}{ Volume } \\
\hline \multirow[t]{2}{*}{ Equation 3.12} & 2113605 & 74906 & & -5688238 & -22811549 & \\
\hline & $<0.0001^{* * *}$ & 0.5921 & & $0.0891 *$ & $0.0024 * * *$ & \\
\hline \multicolumn{7}{|l|}{ Volume } \\
\hline \multirow[t]{2}{*}{ Equation 3.13} & $2,160,311$ & 139,884 & & $-5,857,066$ & & $-4,922,246$ \\
\hline & $<0.0001^{* * *}$ & 0.3487 & & $0.0915^{*}$ & & $0.0568 *$ \\
\hline
\end{tabular}




\section{Conclusions}

This study is the first to empirically examine stock market manipulation cases on the HKSE. Stock market manipulation is observed to negatively impact market efficiency measures both at the time of manipulation and in the period following manipulation. The HSKE could not return to pre-manipulation efficiency measures.

Both the BAS and the PBAS are observed to widen at the time of manipulation and remain wide afterwards. This result accurately reflects the market microstructure assumption that information asymmetry risk is built into spreads by rational investors. Manipulation is also associated with increased volatility and reduced volume as investors exit the market rationally in fear of trading with a manipulator. The resulting impact of market liquidity, efficiency and integrity is negative. The regressions strongly confirm these results with a high degree of significance.

Market prices were observed to rise following manipulation and remain consistently higher. This finding supports the asymmetric price responses first suggested by Allen and Gorton (1992). The worrying implication is that manipulation is both possible and profitable as trade-based manipulators are seemingly able to raise prices by trading and exit their positions at those artificially high prices. The results also found no justification to claims that larger traders are executed at unfavourable prices. This surprising result suggests the notion of trade size as a proxy for information asymmetry of Easely and O'Hara (1987) may be misplaced. Manipulators seemingly are able engage in large, profitable trades.

These results go some way to refuting the suggestion of Fischel and Ross (1991) that the legal notion of market manipulation should be dropped because it is always unprofitable and self-deterring. Instead, the results show that markets are not capable of efficiently responding to manipulation. Rational information-seeking investors who normally keep markets efficient may be the unfortunate victims of market manipulation. The results therefore provide an empirical justification as to why manipulation must continue to be prohibited by law and robustly and effectively prosecuted. 


\section{References}

Books/Journals:

Aggarwal, R.,K., Wu, G. 2006, 'Stock Market Manipulations', Chicago Journal of Business, vol.79, no.4, pp 1915-1953.

Allen, F., Gale, D. 1992, 'Stock Price Manipulation' The Review of Financial Studies, vol.5, issue 3, pp. 503-529. http://dx.doi.org/10.1093/rfs/5.3.503

Allen, F., and Gorton, G. 1992, 'Stock price manipulation, market microstructure and asymmetric information', European Economic. Review, vol. 36, pp. 624-630. http://dx.doi.org/10.1016/0014-2921(92)90120-L

Arjunan, K. 2003, 'Overseas Notes - Hong Kong, Singapore and Malaysia', Corporations and Securities Law Journal, vol. 21, pp. 336-318.

$\mathrm{Au}, \mathrm{A} .1988$, 'Regulating Securities Fraud and Market Manipulation in Hong Kong: Part XII of the Securities Ordinance', Hong Kong Law Journal, vol. 18, pp. 2548.

Avgouleas, E. 2005, The Mechanics and Regulation of Market Abuse, $1^{\text {st }}$ ed, Oxford University Press, Oxford. http://dx.doi.org/10.1093/acprof:oso/9780199244522.001.0001

Bagehot, W., 1971, 'The Only Game in Town' Financial Analysts Journal, vol.27, no.2, pp 12-14. http://dx.doi.org/10.2469/faj.v27.n2.12

Bagnoli, M., Barton, L.,L. 1996, 'Stock Price Manipulation through Takeover Bids', vol. 27, no.1, pp. 124-147.

Bagnoli, M. and Lipman, B.L. 1996, 'Stock Price Manipulation Through Takeover Bids' The RAND Journal of Economics vol. 27, no. 1, pp. 124-147 http://dx.doi.org/10.2307/2555795

Ball, R., Brown, P. 1968, 'An Empirical Evaluation of Accounting Income Numbers', Journal of Accounting Research, vol. 6, no. 2, pp. 159-178. http://dx.doi.org/10.2307/2490232

Benabou, R., Laroque, G. 1992, 'Using Privileged Information to Manipulate Markets: Insiders, Gurus and Credibility', The Quarterly Journal of Economics, vol. 107, no. 3, pp. 921-958. http://dx.doi.org/10.2307/2118369

Bodie, Z, Ariff, M, da Sliva Rosa, R, Kane, A \& Marcus, AJ 2007, Investments, McGraw-Hill/Irwin, North Ryde.

Chakraborty, A., Yilmaz, B. 2004, 'Informed Manipulation', Journal of Economic Theory, vol. 114, issue 1, pp. 132-152. http://dx.doi.org/10.1016/S0022-0531(03)00101-7

Copeland, T.,E., Galai, D. 1983, 'Information Effects on the Bid-Ask Spread' The Journal of Finance, vol.38, no.5, pp 1457-1469. http://dx.doi.org/10.1111/j.15406261.1983.tb03834.x

Easley, D., O'Hara, M. 'Price, Trade Size and Information in Securities Markets', vol. 19, no. 1, pp 69-90.

Fama, E.F. 1970, 'Efficient Capital Markets: A Review of Theory and Empirical Work', The Journal of Finance, vol.25, no.2, p.383-417. http://dx.doi.org/10.2307/2325486

Fischel, D.,R. 1982, 'Use of Modern Finance Theory in Securities Fraud Cases Involving Actively Traded Securities', The Business Lawyer, vol. 38, no. 1, pp. 120.

Fischel, D.,R., Ross, R.,J. 1991, "Should the Law Prohibit "Manipulation" in Financial Markets?', Harvard Law Review, vol.105, no. 2, pp.503-553.

http://dx.doi.org/10.2307/1341697 
Fishman, M., J., Hagerty, K. 1992, 'Insider Trading and the Efficiency of Stock Prices', RAND Journal of Economics, vol. 23, no. 1, pp. 106-122. http://dx.doi.org/10.2307/2555435

Frino, A., Lepone, A. 2012 'The impact of high frequency trading on market integrity: an empirical examination', Driver Review DR24 - Foresight, Government Office for Science (UK) pp. 1-21.

Gerald, B., Nanda, V. 1993, 'Trading and Manipulation Around Seasoned Equity Offerings', The Journal of Finance, vol.48, no. 1, pp. 213-245. http://dx.doi.org/10.1111/j.1540-6261.1993.tb04707.x

Glosten, L.,R, Milgrom, P.,R. 1985, 'Bid, Ask and Transaction Prices in a Specialist Market with Heterogeneously Informed Traders', Journal of Financial Economics, vol.14, no. 1, pp 71-100. http://dx.doi.org/10.1016/0304-405X(85)90044-3

Goldwasser, V. 1999, 'Regulating Manipulation in Securities Markets: Historical Perspectives and Policy Rationales', Australian Journal of Legal History, vol.5, pp 149-200.

Goldwasser, V. 1999, Stock Market Manipulation and Short Selling, Centre for Corporate Law and Securities Regulation, Parkville Australia, CCH Australia Ltd, North Ryde Australia.

Hillion, P., Suominen, M. 2005, 'The Manipulation of Closing Prices', Journal of Financial Markets, vol.7, pp. 351-375. http://dx.doi.org/10.1016/j.finmar.2004.04.002

Huang, H. 2009 'Redefining Market Manipulation in Australia: The Role of an Implied Intent Element', Company and Securities Law Journal, vol.27, no. 8, pp. 8-22.

Huddart, S., Hughes, J.,S., Levine, C.,B. 2001, 'Public Disclosure and Dissimulation of Insider Traders', Econometrica, vol.69, no. 3, pp. 665-681. http://dx.doi.org/10.1111/1468-0262.00209

Itzhak, K., Lee, J. 1996, 'Earnings Announcements and the Components of the BidAsk Spread', vol.51, no.4, pp. 1523-1535.

Jarrow, R.A. 1992, 'Market Manipulation, Bubbles, Corners and Short Squeezes', Journal of Financial and Quantitative Analysis vol.27, no.3 pp. 311-336. http://dx.doi.org/10.2307/2331322

Kim, K.,A., Jungsoo, P. 2010, 'Why do Price Limits Exist in Stock Markets? A Manipulation-Based Explanation', European Financial Management, vol. 16, issue. 2, pp. 296-318. http://dx.doi.org/10.1111/j.1468-036X.2008.00456.x

Kose, J., Narayanan, R. 1997, 'Market Manipulation and the Role of Insider Trading Regulations', Chicago Journal of Business, vol.70, no. 2, pp. 217-247.

Krinsky I. and Lee J. 1996, 'Earnings Announcements and the Components of the Bid-Ask Spread' The Journal of Finance vol. 51, no. 4, pp. 1523-1535. http://dx.doi.org/10.1111/j.1540-6261.1996.tb04078.x

Klaus, A. 1972, 'Price Impacts of Block Trades on the New York Stock Exchange', The Journal of Finance, vol. 27, no. 3, pp.569-588. http://dx.doi.org/10.1111/j.1540-6261.1972.tb00985.x

Kraus, A., and Stroll, H. R. 1972, Price Impacts of Block Trading on the New York Stock Exchange.' Journal of Finance, vol. 27, pp. 569-588. http://dx.doi.org/10.1111/j.1540-6261.1972.tb00985.x

Kumar, P., Seppi, D.,J. 1992, 'Futures Manipulation with 'Cash Settlement', The Journal of Finance, vol. 67, no. 4, pp. 1485-1502. 
Kyle, A.,S. 1985 'Continuous Auctions and Insider Trading', Econometrica, vol. 53, no. 6, pp. 1315-1335. http://dx.doi.org/10.2307/1913210

Lawrence, L.,D. 1993, 'Puppet Masters or Marionettes: Is Program Trading Manipulative as Defined by the Securities Exchange Act of 1934?', Fordham Law Review, vol.61, no.6, pp. 207-243.

Leas, P.,L. 1974, 'The Measure of Damages in Rule 10b-5 Cases Involving Actively Traded Securities', Stanford Law Review, vol. 26, no. 2, pp. 371-398. http://dx.doi.org/10.2307/1227792

Loke, F.H. 2007 'The Investors' protected interest against market manipulation in the United Kingdom, Australia and Singapore', Australian Journal of Corporate Law, vol.21, no.1, pp. 22-50.

Loss, L., Seligman, J. 2004, Fundamentals of Securities Regulation, $5^{\text {th }}$ ed, Aspen Publishers, Aspen.

Macey, J.,R., Miller, G.,P., Mitchell, M.,L., Netter, J.,M. 1991, 'Lessons from Financial Economics: Materiality, Reliance, and Extending the Reach of Basic v. Levinson', Virginia Law Review, vol. 77, pp. 1017- 1049.

Modigliani, F., Miller, M.,H. 1958, 'The Cost of Capital, Corporate Finance and the Theory of Investment', The American Economic Review, vol.48, no.3, pp. 261297.

Niederhoffer, V., Osborne, M., F.,M. 1966, 'Market Making and Reversal on the Stock Exchange', Journal of the American Statistical Association, vol. 61, no. 316, pp. 897-916. http://dx.doi.org/10.1080/01621459.1966.10482183

Poser, N. 1986, 'Stock Market Manipulation and Corporate Control Transactions', University of Miama Law Review, vol.40, no.3, pp. 671-735.

Scholes, M. 1969, 'A Test of the Competitive Hypothesis: The Market for New Issues and Secondary Offerings' Unpublished PhD thesis, University of Chicago.

Scwert, W. 1981, 'Using Financial Data to Measure Effects of Regulation', Journal of Law and Economics, vol. 24, no. 1, pp. 121-158. http://dx.doi.org/10.1086/466977

Thel, S., 1994, ' $\$ 850,000$ in Six Minutes - The Mechanics of Securities Manipulation', Cornell Law Review, vol. 79, pp. 219- 298.

Tumarkin, R., Whitelaw, R.,F. 2001, 'News or Noise? Internet Postings and Stock Prices', Financial Analysts Journal, vol. 57, no. 3, pp. 41-51. http://dx.doi.org/10.2469/faj.v57.n3.2449

Van Bommel, J. 2003, 'Rumours', The Journal of Finance, vol. 58, no. 4, pp. 14991519. http://dx.doi.org/10.1111/1540-6261.00575

Vanden, J., M. 2005, 'Digital Contracts and Price Manipulation', vol. 78, issue. 5, pp. 1891-1916.

Vila, J.,L. 1989, 'Simple Games of Market Manipulation', Economic Letters, vol. 29, issue 1, pp. 21-26. http://dx.doi.org/10.1016/0165-1765(89)90167-5

Zvi, B., Ariff, R.D.S.R., Kane, A., Marcus, A.J. 2007, Investments, McGraw-Hill, North Ryde Australia.

Cases:

Australian Securities Commission v Nomura (1998) 160 ALR 246.

ASIC v Soust [2010] FCA 68.

Cargill, Inc v Hardin, 452 F.2d 1154, 1163 (8 ${ }^{\text {th }}$ Cir. 1971), 406 U.S. 932 (1972).

Director of Public Prosecutions (Cth) v JM (2013) 298 ALR 615.

Fu Kor Kuen v. HKSAR (FACC No. 4 of 2011, May 24, 2012). 
HKSAR v Chan Chin-yuen and others (2008) DCC683/2008.

HKSAR v Fu Kor Kuen Patrick [2011] 1 HKLRD 655, CACC 179/2010.

Santa Fe Industries Inc v Green 430 U.S. 462, 477 [1977].

Securities \& Futures Commission v Choi Wai Zak [2003] 1 HKC 30 HCMA

$264 / 2002$.

Reports:

Australian Securities and Investments Commission (ASIC) March 2013, Report 331 Dark Liquidity and high-frequency trading.

Corporations and Markets Advisory Committee 2009, Aspects of Market Integrity.

Investment Industry Regulatory Organisation of Canada (IIROC) 2012 IIROC Notice 12-0221 - Rules Notice - Request for Comments - UMIR - Proposed Guidance on Certain Manipulative and Deceptive Trading Practices.

Internet Sources:

Liondis, G. 2013 'ASIC backs down on dark pool, high-frequency trading' The Australian Financial Review, 18 June, viewed 20 June 2013, http://www.afr.com/p/business/financial_services/asic backs down_on_dark_pool high swYh6UbErAwTwWKb199nXN.

Metherell, L. 2012 'David Jones takeover bid withdrawn' Australian Broadcasting Authority, 3 June, viewed 6 August 2013,

http://www.abc.net.au/news/2012-07-02/dj-takeover-bid-withdrawn/4105234.

Securities and Futures Commission 2007, 'SFC Successfully Prosecutes Han Sze Chao Richard \& Super Glory International Ltd for Market Manipulation', viewed 28 September 2013, http://www.sfc.hk/edistributionWeb/gateway/EN/news-andannouncements/news/doc?refNo=04PR135.

Verrender, I. 2009, 'Making a mint as inquiry founders', The Sydney Morning Herald, viewed 28 September 2013, http://www.smh.com.au/business/making-a-mint-asinquiry-founders-20090323-97iw.html\#ixzz1VZ41Qs8n.

World Federation of Exchanges 2013, Monthly Report - August 2013, viewed 19 August 2013, http://www.world-exchanges.org/statistics/monthly-reports. 